\title{
Kounis Syndrome; anaphylaxis causing coronary occlusion
}

\section{Natanya Moloney, BMedSt}

Medical student, Bond University, Gold Coast, QLD, Australia

Natanya.moloney@student.bond.edu.au

Scott Paget, MBBS, BSc BioEng, FACEM

Senior Registrar, Department of Emergency Medicine, Gold Coast Hospital, QLD, Australia; Griffith University, Gold Coast, QLD, Australia

Scott.Paget@health.qld.gov.au

Gerben Keijzers, MSc (Biomed Health Sci), MB BS, FACEM, PhD

Emergency Physician, Department of Emergency Medicine, Gold Coast Hospital,

QLD, Australia; Professor (adjunct), Bond University, Gold Coast, QLD, Australia Griffith University, Gold Coast, QLD, Australia

Gerben.Keijzers@health.qld.gov.au

Word Count: 586 
Dear Editor,

A 53-year-old male was transferred by ambulance to our centre with retrosternal chest pain immediately after treatment for anaphylaxis. The patient initially sought care after experiencing shortness of breath, diaphoresis, nausea and dizziness following ingestion of amoxicillin/clavulanic acid. On arrival paramedics found the patient collapsed on his premises with cyanosed lips and generalised urticaria. The patient was treated with two injections of $0.5 \mathrm{mg}$ adrenaline IM, and additionally given $700 \mathrm{ml}$ intravenous isotonic fluid and $200 \mathrm{mg}$ hydrocortisone intravenously. Approximately two minutes after the second dose of IM adrenaline and resolution of anaphylaxis symptoms, the patient began to experience central chest pain. ECG performed on route to our centre displayed sinus tachycardia and ST-elevation in leads II, III and aVF. Aspirin, fentanyl, heparin and ticagrelor were administered and the cardiac catheter laboratory was activated pre-hospitally. On arrival in the Emergency Department (ED), the patient had minimal pain and vitals were BP 140/70, HR 140 and RR 20; peripheries were warm and well perfused. A subsequent ECG showed atrial fibrillation with presence of ST changes. The patient was transferred to the cardiac catheter laboratory where coronary angiogram revealed $50 \%$ stenosis of the LAD, minor disease of the circumflex, $60 \%$ stenosis mid RCA and $99 \%$ stenosis distal RCA (Figure 1). Drug eluting stents were placed in the right coronary artery, and the patient had an uneventful recovery.

The concurrence of acute coronary syndrome with hypersensitivity reactions is known as Kounis Syndrome. ${ }^{1}$ There are three variants of the syndrome in decreasing prevalence.

Type I: Allergy-related angina due to coronary spasm; Type II: Allergy-related myocardial infarction due to plaque rupture and thrombus formation and Type III: Drug eluting stent thrombosis secondary to hypersensitivity reaction. Type II patients are believed to have inactive but quiescent pre-existing atheromatous plaques. An allergic insult then leads to plaque erosion or rupture and myocardial ischaemia. ${ }^{2}$ Type I Kounis Syndrome is most frequently reported (72.6\% of cases), with Type II representing $22.3 \%$ of cases and Type II $5.1 \%{ }^{3}$ 
The incidence of Kounis Syndrome is difficult to estimate, and it is likely that the condition is under-reported, ${ }^{3}$ with limited Australian cases reported in the literature. A prospective study ${ }^{4}$ estimated the incidence of Kounis Syndrome to be 19.4 per 100 000 admissions. $^{4}$

Myocardial infarction in these circumstances can also be attributed to the therapeutic use of adrenaline for anaphylaxis, although IM adrenaline induced myocardial infarction is very uncommonly reported. ${ }^{2}$ In this case, it is likely that the patient suffered Kounis Syndrome Type II, as there was evidence of coronary artery disease and had pre-existing atheromatous plaques as well as plaque rupture during catheterisation.

Anaphylaxis has the potential to alter the traditional initial management of STEMI, with Table 1 summarising management considerations for the three variants of Kounis syndrome.

Nitrates may not be appropriate in the setting of anaphylaxis as they may worsen hypotension. Additionally, opioids such as morphine may induce mast cell degeneration, aggravating the anaphylaxis. Beta blockers counteract the actions of adrenaline in anaphylaxis and some literature suggests not using them at all when acute coronary syndrome is suspected in the setting of anaphylaxis. ${ }^{1}$ Even aspirin is potentially detrimental, producing more anaphylaxis mediators through cyclooxygenase inhibition. ${ }^{1}$

These medicines are commonly used in the early hospital management of acute coronary syndrome, and it is unclear what the optimal management for patients with concurrent anaphylaxis and myocardial infarction is. This case highlights the need to outweigh the relative urgency and risk of anaphylaxis and its treatment against the risks of acute coronary syndrome and its treatment. 


\section{References}

1. Fourie $P(2016)$ Kounis syndrome: a narrative review, Southern African Journal of Anaesthesia and Analgesia. 2016;22:2, 72-80, DOI:

10.1080/22201181.2016.1154309

2. Jayamali $W$, Herath $\mathrm{H}$, Kulathunga, A. Myocardial infarction during anaphylaxis in a young healthy male with normal coronary arteries- is epinephrine the culprit?. BMC cardiovascular disorders. 2017;17(1), 237. doi:10.1186/s12872-017-0670-7

3. Abdelghany M, Subedi R, Shah S, Kozman H. Kounis syndrome: a review article on epidemiology, diagnostic findings, management and complications of allergic acute coronary syndrome. Int J Cardiol. 2017;232(Suppl C):1-4

4. Akoz $\mathrm{A}$, Tanboga $\mathrm{H}$, Emet $\mathrm{M}$ et al. A prospective study of kounis syndrome: Clinical experience and cardiac magnetic resonance imaging findings for 21 patients. Acta Medica Mediterranea. 2013;29. 811-816.

5. Fassio F, Losappio L, Antolin-Amerigo D et al. Kounis syndrome: A concise review with focus on management. European Journal of Internal Medicine. 2016;30:7-10.

Conflicts of interest: GK is a section editor for Emergency Medicine Australasia

Figure 1 - $\mathrm{PCl}$, prior and post stent insertion in RCA

PCl: Percutaneous Coronary Intervention; RCA: Right Coronary Artery Arrow indicates occlusion prior to stenting 
Table 1 - Management considerations for Kounis syndrome variants

\begin{tabular}{|c|c|c|}
\hline Type I & Type II & Type III \\
\hline $\begin{array}{l}\text { May benefit from } \\
\text { treatment of allergic } \\
\text { reaction, circumventing } \\
\text { further complications. }{ }^{5}\end{array}$ & $\begin{array}{l}\text { Acute coronary event } \\
\text { protocol. }{ }^{5} \\
\text { Caution with nitrates in } \\
\text { hypotension. }{ }^{1}\end{array}$ & $\begin{array}{l}\text { Acute coronary event } \\
\text { protocol. }{ }^{5} \\
\text { Caution with nitrates in } \\
\text { hypotension. }{ }^{1}\end{array}$ \\
\hline $\begin{array}{l}\mathrm{H} 1 \text { and } \mathrm{H} 2 \text { antihistamines } \\
\text { (e.g. diphenhydramine 1- } \\
2 \mathrm{mg} / \mathrm{kg} \text { ) for non-severe } \\
\text { symptoms. }^{5}\end{array}$ & $\begin{array}{l}\text { Beta-blockers } \\
\text { contraindicated }{ }^{1,5} \text {, } \\
\text { patients may benefit from } \\
\text { qlucagon } 5\end{array}$ & $\begin{array}{l}\text { Urgent aspiration of } \\
\text { intrastent thrombosis. }{ }^{5} \\
\text { Mast cell stabilisers alona }\end{array}$ \\
\hline $\begin{array}{l}\text { Must be given slowly as } \\
\text { they can precipitate } \\
\text { hypotension and } \\
\text { compromise coronary } \\
\text { blood flow. }{ }^{5}\end{array}$ & $\begin{array}{l}\text { Opioids administered with } \\
\text { caution }{ }^{1,5} \text {, consider } \\
\text { fentanyl. }^{1}\end{array}$ & $\begin{array}{l}\text { with corticosteroids and } \\
\text { anti-histamines to } \\
\text { potentially alleviate } \\
\text { allergic symptoms from } \\
\text { stent implantation. }^{5}\end{array}$ \\
\hline $\begin{array}{l}\text { There are no drugs of } \\
\text { choice in initial severe } \\
\text { allergic reaction. }{ }^{5}\end{array}$ & & $\begin{array}{l}\text { Opioids administered } \\
\text { with caution }^{1,5}, \text { consider } \\
\text { fentanyl. }^{1}\end{array}$ \\
\hline
\end{tabular}

Type I: Allergy-related angina due to coronary spasm; Type II: Allergy-related myocardial infarction due to plaque rupture and thrombus formation; Type III: Drug eluting stent thrombosis secondary to hypersensitivity reaction 


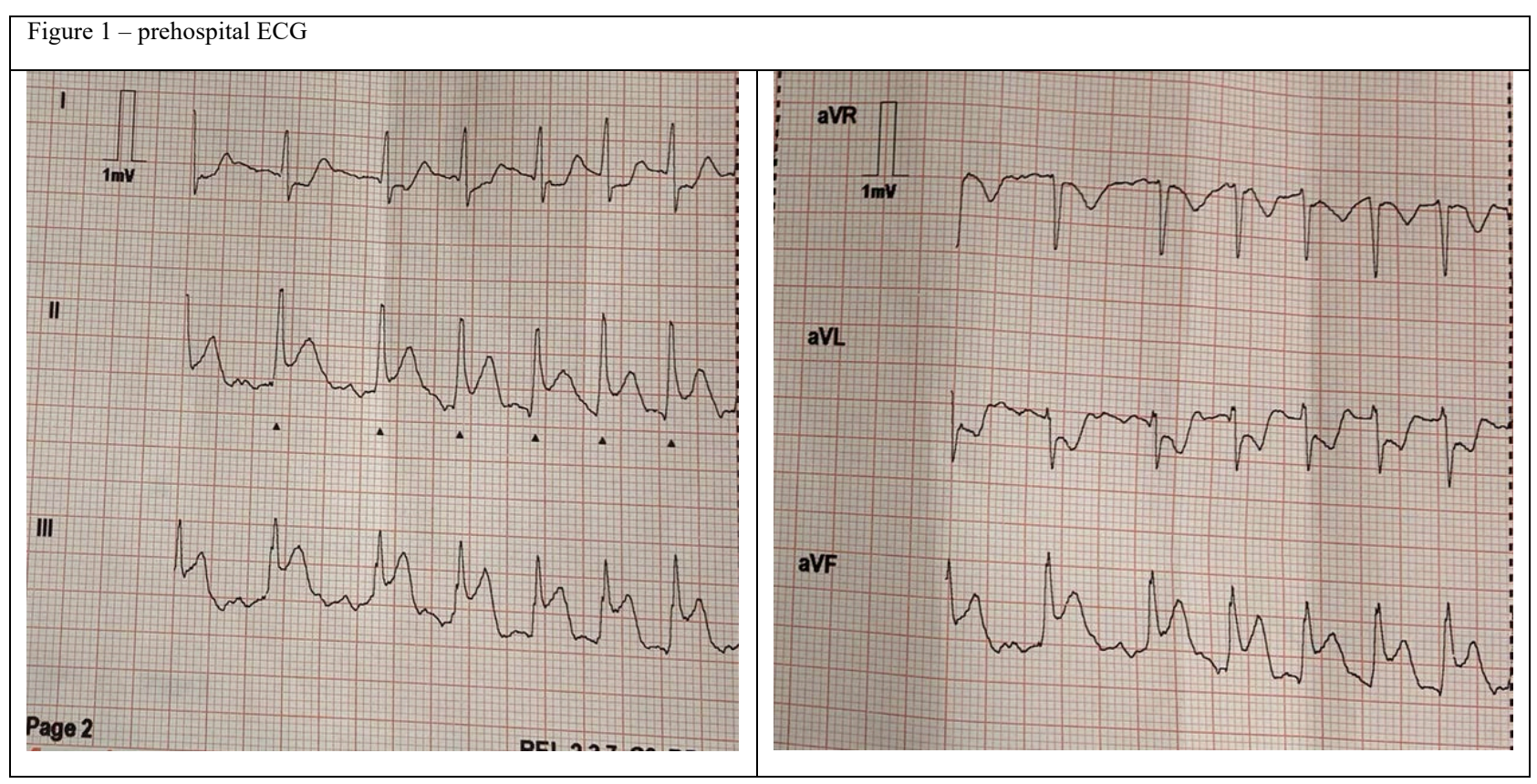




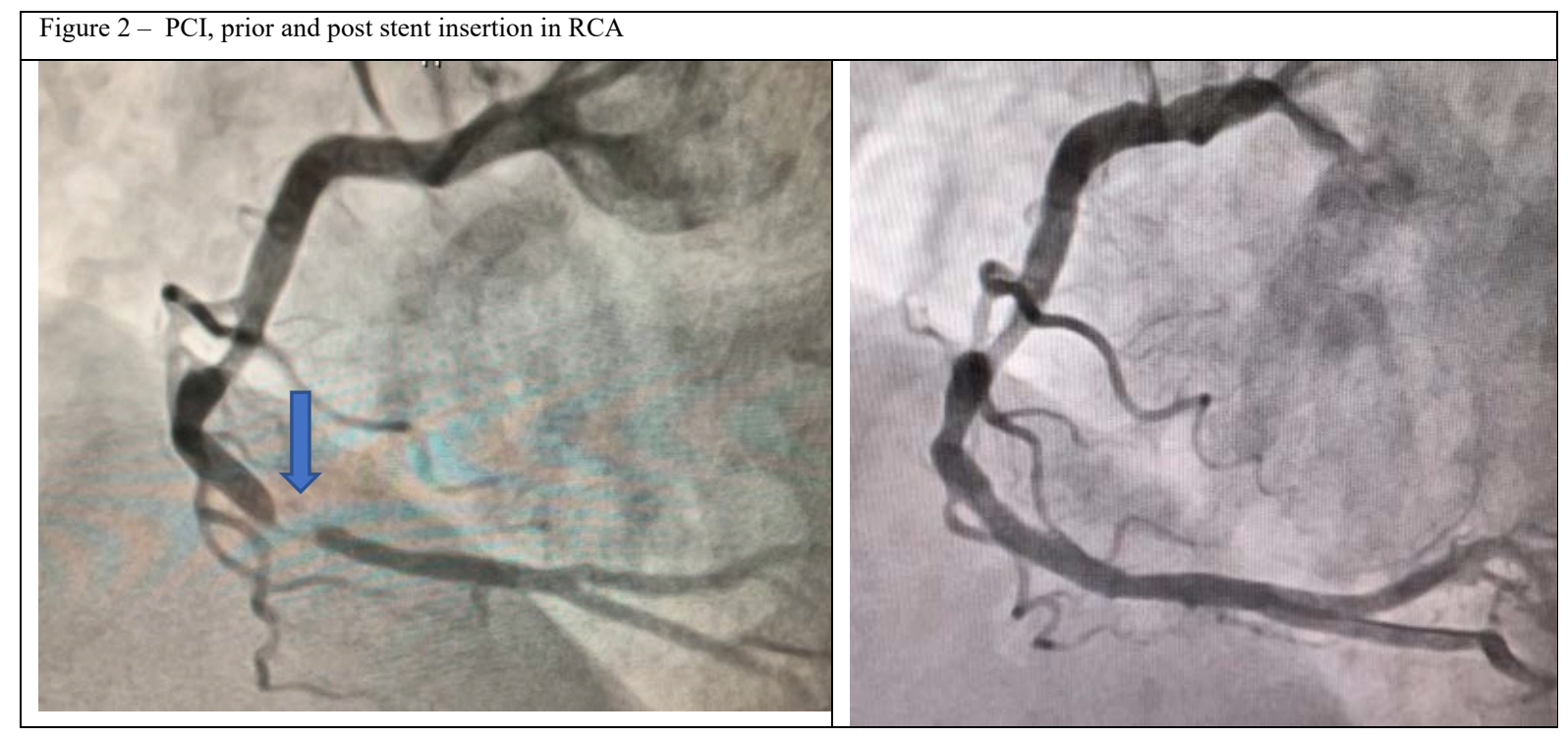

PCI: Percutaneous Coronary Intervention; RCA: Right Coronary Artery Blue arrow indicates occlusion prior to stenting 